Philosophy of Science 14 (1981)

Two Kinds of Philosophical Analysis

David F. Pears

Twentieth century analytical philosophy presents a complex pattern of development which would take a long time to describe in detail. In this lecture my task will be less ambitious. I shall merely pick out two elements in the pattern, two opposed tendencies, which are discernible throughout the century. One is the tendency to look for analysis on or near the surface of ordinary language, while the other explores a deeper level.

That is rather a vague way of drawing the distinction that I have in mind, but it is clear enough to enable us to place many philosophers on one side of the dividing line or the other. loore and Austin exploited the upper strata, but Russell's investigations went deeper. Wittgenstein is a more complicated case, because his early philosophy belongs with Russell's while his later philosophy, though it is not at all like Noore's and Austin's, is the result of work done at the same level.

These examples also illustrate another contrast, wittgenstein in his later work and Austin in most of his work shared a bias against philosophical theories, while on the other side of the dividing Iine Russell always took the philosoer's task to be the construction of theories and Nittgenstein agreed with him until about 1930. So we have not only the original contrast between those who work near the surface of language and those who go deeper but also another, apparently connected contrast between those who avoid theories and those who seek them.

My main. theme will be the first of these two contrasts and a simple illustration may serve to fix its character. Suppose that someone were asked to explain the meaning of the word "water" when there was none around. He might 
list the phenomenal properties by which we recognize water or he might give its. chemical composition. Then a philosopher is asked what sort of result he is trying to get when he is engaged in philosophical analysis, he may give an answer of the first kind and say that to analyze a word is to give the everyday criteria of its application; or alternatively, he may give an answer of the second kind and say that it is to give the real nature of the thing to which the word applies. This example, borrowed from Putnam's ${ }^{I}$ and Kripke's ${ }^{2}$ account of natural kinds, illustrates the contrast that I am going to discuss.

There is a connection between this contrast and the contrast between theoretical and anti-theoretical philosophy, but the connection is not a very close one. This is shown by the example. For a philosopher who is content with the everyday criteria for applying words may well have a theory of meaning too -verificationism. It is just a different theory from the one adopted by philosophers who rely on the real natures of the things to which the words are applied. Therefore, the distinction between surface and depth analysis does not line up with the distinction between theoretical and anti-theoretical philosophy. Nevertheless, there is a certain connection between the two distinctions. A philosopher who thinks that the meanings of words cannot simply be gathered from their everyday use must have a positive theory telling us where else to look and what else we might expect to find. Otherwise, there would be no reason to accept his negative point. There is an onus on the side that says that things are not what they appear to be. So in the example that I have been using the idea that the meaning of a word is determined hy the reat nature of the thing designated it is the germ of a substantial theory. The theory begins to

1. H. Putnam, "The Keaning of "Meaning"' in Fhilosophical Papers, vol. 2, Cambridge, 1975.

2. S. Kripke, Naming and Necessity, Oxford, 1980, Lecture III. 
unfold when we ask how the real nature of the thing is discovered. In this case the answer is clear: science tells us what the nature of water is. Perhaps there are other cases in which the theory would not be scientific. But a deep analysis will always need the support of some theory, because it goes against the appearances.

On the other side of the dividing line philosophers may have theory but they need not have one: The reason why they need not have one is interesting. It is that in the world of meaning we do not start with a common-sense theory of what meaning is. Perhaps this is because meening is too close to us, too much part of the texture of our lives. Anyway, the appearances do not point towards eny comron-sense theory of meaning. They do not point towards a comrion-sense theory of understanding meanings but that is a different matter, because, though vie nay be sure that people understand the meaning of a word if they agree in its application, we may not be at all sure what meaning is. That is why surface anaiysis need not be associated with any theory and why witigenstein after 1930, and Austin in most of his work seemed to be able to operate, and inay really have operated without any theory of meaning.

When Russell visited Oxford in the middle of $1950^{\prime} \mathrm{s}$, he came as a hostile critic of a school of philosophy which seemed to him to be more unified than it really was. He assumed that there was no difference between the attitudes of Ryle and Strawson to ordinary language and Austin's attitude. We questioned him about his own philosophical method and I remember that the discussion became quite heated at times. He said that he was not interested in the language of peasants. He also said, with more justice, that we in Oxford had come to philosophy from the study of Iiterature rather than from science and mathematics and that this was a disadvantage, because it made us more interested in words than in things. There are echoes of this discussion in the last chapter of his 
book, My Philosophical Development ${ }^{1}$. He there connects the work of the Oxford school, still completely undifferentiated; with the later work of wittgenstein. He does not actually use the word "work", because he regards the: study of language as a lazy method incapable of achieving any significant resultis.

Austin's writings are certainly very different from the kind of thing that Russell published in the first two decades of the century. Wittgenstein's posthumous books are also very different from his earlier Tractatus Logico-philosophicus $^{2}$. So much is obvious. It is less obvious, but important that, though the two later development both keep close to the surface of language, they have quite different characters. However, that is a point that cen wait for a moment. It is best to begin with what came first, the early philosophy: of irussell and Wittgenstein.

Sö my first topic will be logical atomism. "Yy main purpose will be to use it as an example of deep analysis. But I also want to. show that there is some tension within the theory itself, because both Russell and wittgenstein felt that there was a danger that it might lose contact with the actual use of words and so they both often showed signs of wanting to bring the analysis up closer to the surface. I shall, therefore, use logical atomism to illustrate my theme in two different ways. First, there will be an over-all contrast between deep : analysis guided by the theory of logical atomism and surface analysis, and second, within the theory: itself the same contrast will show itself in a tension which actually produced two different versions of it.

The theory is easier to understand if we begin with the version that is . closer to the surface, because that is the version that Russell developed first.

I. B: Russell: 1hy Philosophical Development, Iondon, 1957.

2. I. Wittgenstein: Tractatus Logico-Philosophicus, London, 1922. 
We may then proceed to the deeper version developed by wittgenstein. I shall cail the latter the "w-version" and the former the "R-version". These names do not imply that each philosopher adhered to the 'version of the theory that he originated. That was no the situation. Both oscillated between the two versions for reasons that I shall explain later.

Russell was an empiricist and the R-version of logical atomism was a direct descendant of Hume's atomism. Hume believed that the ideas of certain sensory properties cannot be acquired by way of any definitions connecting them with other properties, and can only be acquired from the corresponding impressions ${ }^{I}$. Russell believed that the names' of these properties cannot be understood by way: of definitions connecting them with other properties and can only be understood through acquaintance with the properties themselves ${ }^{2}$. Iike Hume, he thought of: definitions as devices for taking things to pieces in one's mind and so, like Hume, he called these terminal properties "simple properties". Then, unlike Hume, he extended the theory to particulars and their names. If the name of a. particular cannot be understood through any definition, it is a simple particular and its name is a logically proper name. " '

There are two points that I want to emphasize about the R-version of logical atomism. First, it is an empiricist theory which is supposed to explain how people actualiy learn the meanings of words. Second, it is a theory supported by an empiricsi argument.

The firt of these two points needs to be illustrated by examples. Russell, like Hume, used shades of colour as examples of simple properties. So the idea is that the meaning of a word like "scarlet" can be learned only through actual"

1. D. Hume: A Treatise of Human Nature, Bk. I, Pt. I, ch. i.

2. See 'The Philosophy of Logical Atomism', in Essays, Logic and Knowledge, ed. R. C. Marsh, London, 1955. 
acquaintance with the colour. But the colour is a simple quality that is familiar and accessible to us. We, therefore, are being offered an empiricist theory of the meaning of the word.

The second point about the R-version is that it is supported by an empirical argument Russell claimed that, if you take any descriptive word and anaIyze it, you will as a matter of discoverable fact make your way down to logical atoms like the colour scarlet. You will know when you reach these logical atoms, because you will find that acquaintance with them is the only way of learning the meanings of its name. Indeed, the things actually are the meenings of names occurring at the terminal level of anlysis.

There is another point about the R-version that should be noted. When acquaintance with a thing provides the only way of learning the mearings of its name, Russell thought it irrelevant that its name might have a definition. Perhaps the name of a colour is definable by its wave-length, but that dons rot provide us with an alternative way of learning its meaning and so it does not count as an analysis. In the R-version simulicity is established by the unevoilability of acquaintance as a metrod of learning the mesning of a word.

It is at this point that the W-version divergesfrom the k-version. Wittgenstein's view was that simplicity had nothing to do with the lecrning of the meanings of words. He used a different criterion of simplicity. He maintained that a thing is simple if and only if its name does not produce any logical connections between any proposition in which it occurs and any other proposition belonging to the same level. These logically independent and fundamental propositions he called "elementary:" ${ }^{I}$. This is evidently a stricter criterion of simplicity than Russell's. Shades of colour pass Russell's test but they do not pass this one.

I. Tractatus Logico-Philosophicus, $4.21-4.211$ 
I have called the level at which logical atoms occur in the R-version of the theory the "terminal level". We may call the level at which they occur in the W-version the "ultimate level", which, of course, is deeper and, therefore, more remotely related to our criteria for applying the words in our vocabulary. Wittgenstein says: "Man possesses the ability to construct languages capable of expressing every sense without having any idea how each word has meaning or what its meaning is - just as people speak without knowing how the individual words are produced"I ${ }^{I}$. That statement could not have been made in an exposition of the R-version.

In the w-version it is made about every description word in our vocabulary and in that highly generalized form it is very implausible. It becomes plausible only when it is restricted to certain types of descrintion words. For example, a natural kind, like water, does show a gap between the ordinary criteria for applying its name and the real nature of the thing. But it can hardly be right to extend this deep kind of analysis to every type of word in our vocabulary. It is, for example, impossible to see how it could be extended to words for artefacts. Nevertheless, Nittgenstein did extend it to all types of descriptive words. He thought that he had an argumient that forced him to do this. The argument was based on Russell's idea that a definition takes a thing to pieces. Now in the F-version the logical atoms have names like "scarlet" and "turquoise", which do produce logical connection between the propositions in which they occur, but the W-version took these logical connections to indicate definability and, so, given Wittgenstein's basic idea, to indicate com lexity. But, he argued, if this kind of complexity. existed at every level of analysis, language could never get going ${ }^{2}$. For Ianguage begins when words are applied to things...and, iff aII

\section{Ioc. cit.}

2. See Tractatus Logico-Philosophicus, 2.0211 and 3.23 
things were composite, the application of a word to a thing would always presuppose the truth of a further proposition giving the composition of the thing. Therefore, language can get going only at a level at which the application of words to things does not presuppose any further truths; because the things are not composite. Any: other beginning would be impossible, because it would not really be a beginning.

I shall not make detailed comments on the validity of this argument. It is evidently: quite unlike the empirical argument used by Russell. It relies on an a priori theory which tells us how language must be set up rather than how it is set up as a matter of empirical fact. This theory: borrows the idea of composition from natural science and so extends to all types of words a pattern of analysis which may be appropriate only to words for natural kinds. But the trouble is that when this pattern of analysis is extended to all kinds of words, the idea of-composition loses its scientific content without acquiring any other kind of content to replace it. Whow the scientific theory that connects the ordinary use of the word "water" with its deep analysis, but we do not know what. theories would establish this connection for words of other types.

Wittgenstein invented the W-version, but there are several passages in, Russell's works indicating that he took it over, or, at least, that he was inclined to take it over from Wittgenstein ${ }^{1}$. He appears never to have made a final . : $:$ choice between the W-version and the R-version which he origin ated, and unfortu-: nately he nowhere explains the reasons for his vacillation. But we do know much : more about Wittgenstein's attitude to the two versions. The Tractatus, of course, sets out the H-version ${ }^{2}$. However, before Wittgenstein compiled that book together, he felt serious about the $W$-version. For in his Notebooks 1914-1916 there is a

1. See, for example, his remarks on logical atomism in the last chapter My Philosophical Development.

2. See 5.5562 
long discussion of the relative merits of the $W$-version and another version, which is not precisely formulated but which is certainly closer to the R-version ${ }^{1}$. In a later paper, Some Remarks on Logical Form, he reverted to the R-version definitively ${ }^{2}$

The reason for his earlier vacillation in the Notebooks is interesting. He felt that the W-version might place the complete analysis of ordinary language too far below the level at which it is actually: used. In the discussion of this difficulty he implied that we ought at least to know the form of the complete analysis of an ordinary proposition that we understand. This is like saying that someone who understands the word "measles" ought at least to know that the cause is a virus even if he cannot identify it.

The interesting thing is that when it is a question of the meaning of a word for a natural kind, like measles, this anxiety may be unnecessary. In such cases the meaning really does seem to be a stratified and much of it seems to be out of reach of the layman, who nevertheless manages to apply the word correctly. of course, we need a theory about the structure of the meaning in this kind of case, but we need not despair of finding one. The point that ought to have caused Wittgenstein anxiety was a different one. He need not have been worried about the gap between everyday use and deep analysis in cases where there is a deep analysis, but he ought to have been worried by the fact that his theory of language required a deep analysis in all cases in spite of the implausibility of this general requirement. When Wittgenstein reacted against his. own earliex system, he criticized it in two connected ways ${ }^{3}$. First, he said that the theory of language was too dogmatic in its general delineation of meaning. Language was supposed to conform

I. Notebooks 1914-16, 0xford, 1961, pp. 46-71.

2. 'Some Remarks on Logical Form' in Proceedings of the Aristotelian Society, suppl. vol. IX, 1929.

3. See Ludwig Wittgenstein und Wiener Kreis, ed. B. MicGuinness, p. I82ff. 
to a single pattern, but it would have been wiser to treat it as an open possibility, that it might exhibit a multitude of patterns. Second, the single pattern was supposed to be established by an a priori argument, but it would have been wiser to undertake an empirical investigation in order to discover whether there was one pattern or many. The correction of these two faults was the beginning of his later philosophy. The dogmatism was replaced by open-minded empirical investigation of the phenomenon of language and there was so much detail that it is not always possible to discern the general shape of the results.

However, any reader of Wittgenstein's Philosophical Investigations will feel immediately that he is in a different world. There are no theories about. remote strata in the structure of meanings. Meaning is use and everything is on the surface. The method is to describe the personal lifel of human beings, which is presented as a very special kind of history, played out between the outer world of physics and the inner world of neurology. If philosophy was a science, this philosophy would be a mixture of psychology and sociology. But it is not a science, and so, though many of the facts used by. Nittgenstein come from these two areas, they are used in a special way that lays them under a contribution to. philosophy. That is not so easy is to see how the contribution is made.

It is perhaps best to approach this question by asking what wittgenstein does not do in his later writings. He does not use the successes of physics as a model for philosophical analysis. He is not even interested in the philosophy of science. He mentions scientific extensions to ordinary language and compares them to suhurhs huict. amund an old citv, but it is the old city that interests. him. One reason for this narrowness of focus may have been that he believed that a theory of language makes better progress if it starts from what is simple and fariliar. Certainly, he thought that the way to understand the phenomenon of meaning is to describe the role of language in our lives. 
But he also had a stronger reason for avoiding the kind of realism in the theory of meaning that is often adopted by philosopher of science. His new investigation of language convinced him that realists and conventionalists are both wrong. The realist theory, that meanings are fixed by the natures of . things, does not provide the independent support that it appears to provide. For it depends on the identification of the things, and that in turn depends on the criteria used by people who identify them. That might suggest that conventionalists are right when they say that meanings are fixed by criteria and criteria are laid down in rules. But Wittgenstein argues that the future applications of rules are not determined in advance, and so rules are equally incapable of providing indendent support.

If neither realism nor conventionalism is right, what, is: left? It is at this point that Wittgenstein falls back on human life and practice. He suggests that the founstion of language is human agreement in judgement ${ }^{I}$. This is the theory that Hao Wang calls "anthropologism" and vittgenstein even extends it to mathenatics ${ }^{2}$.

At this point it becomes clear that the method and the results of wittgenstein's later work cannot be held apart from one another. For the method is to' investigate the role of language in our lives and the result is that the foundation of language is human agreement in judgements. If it were objected that the method makes it impossible to reach any other result, Wittgenstein would reply that he offers exhaustive critiques of the two rivals, realism and conventionalism, and he would claim that his result is the only one that survives critical examination.

1. I. Wittgenstein: Philosophical Investigations, 8241.

2. J. Wittgenstein: Remarks on the Foundations of Nathematics, passim. 
Whatever we may think of these critiques, the general character of his later philosophy is clear enough. It neglects the language of science and focuses onto ordinary language and its examination of ordinary language keeps very. close to the surface. Everyday criteria are often invoked, but though the mood is verificationist, the theory itself is not officially adopted. It would be not far wrong to call his later philosophy "unsystematic verificationism", provided that we add that the standards of what count as verification are not independently fixed. Certainly, the everyday language and the personal life of human beings are treated as autonomous. This does not lead to any startling results on the outer front, because Wittgenstein is not concerned with the philosophy of physics. But it does lead to some controversjal results on the inner front. There is no doubt about his opposition to any deep neurological analysis of mental words.

I mentioned earlier that, though deep analysis is never anti-theoretical, surface analysis sometimes is. Wittgenstein explicitly claimed that his kind of surface analysis was completely anti-theoretical. Philosophy, he said, is purely descriptive and in no way explanatory. ${ }^{I}$. It simply notes the part played by language in the personal lives of human beings and leaves it at that.

This seems to contradict the interpretation that I have been giving of his later work. However, the two interpretations are not irreconcilable. He regarded his later philosonhy as an antidote both to realism and to conventionalism, but he believed that, though these are both theories, the antidote is not another theory. It merely records the relevant facts in a way that is supposed to show that the phenomenon of meaning provides no besis for any theory. If we disagree with him and say, as I have been saying, that what replaces a theory must itself be a theory, the disagreement is only superficial. For his point

1. See e.g. Philosophical Investigations, \& 599. 
will remain valid and the only change will be in the way in which it is expressed. It will be expressed as the theory that no theory is possible in this area, because these are only the relevant facts.

Wittgenstein often used analogy. to put across his view of his later philosophy. He said that it was like psycho-therapy which removes delusions and cuts mistaken connections. If theories are like maladies the cure will not be another malady. It will produce a'state of mental health which replaces the maladies. ly point is only that the claim, that a philosopher can only describe the relevant facts and is cured when he sees that that his all that he can do, is itself, in a weaker sense, a theoretical claim.

I have little space for my second example of surface analysis, Austin's work. It is plain to any reader of Austin's posthumous books, Sense and Sensibilia and How to do Things with Words, That keeps very close to the surface of language. He always asks how we use a word or type of sentence and he never considers the possibility that the answer might occassionally take us below the surface. He was too aware of I'ivresse des grands profondeurs, like a man who: has alcoholism is his ancestry.

There is an interesting point of contrast here between his work and the Iater work of wittgenstein. Both philosophers lived in a period of domolition. and possible reconstruction and so both were highly critical of the theories of the past, especially of the recent past. The difference between them is that in Wittgenstein's case the theories against which he reacted were his own, because the theory of language developed in the Tractatus combined realism with moderate conventionalism, but the theories against which Austin reacted were those of other philosophers. If Austin was like someone with alcoholism in his ancestry, Wittgenstein was like someone who had it in his blood.

I. Ibid. $\$ 255$. 
It is also worth asking whether after the rejection of existing theories Austin's attitude to replacements was the same as Wittgenstein's. The answer to this question is more complex. Austin's most sustained piece of criticism is Sense and Sensibilia and it certainly does not offer another theory of perception to replace the rejected sense-datum theory. However, this was not because he was always opposed to the construction of theories in philosophy. For in his second book, How to do Things with Words, he does try to develop his own theory of speech-acts and performative expressions. So why is there no similiar undertaking in his first book?

The reason seems to be that his attitude to the construction of philosophical theories changed towards the end of his life. Criticism dominated his earlier work but construction began to appear in the 1950's when he was developing the implications of his own distinction between performative and descriptive expressions. Earlier, when he first took up philosophy, he was appalled by the lack of agreement among those who practice it. Scientists too disagree but at least they have a rethod of reaching agreement. So why are philosophers so unsuccessful at reaching agreement? That is a question often asked in the history of the subject and it has usually led to a new start. Austin's answer was that philosophers use imprecise terminology, which much of his early work was devoted to criticizing. It was only later that he begen to develop theories of his own. So there is a big difference here between his later work and the later work Wittgenstein which was radically opposed to the construction of thenrips.

It is an interesting fact that Austin read a lot of science in his spare time from philosophy. Now there is some truth in Russell's observation that Oxford dons came to philosophy from literature rather than from science and that that was why they were more interested in words than in things. But literature is about something too and you do not need an interest in science to be a realist 
about meaning. In fact, Austin was interested in science, but the effect that it had on him was not entirely the sime as the effect that it had on Russell. It did not make him concerned with the philosophy of science or lead him into a deep analysis of any of the words in our vocabulary. But it did lead him to demand that the terminology of philosophical theories should be as rigorous as the terminology of scientific theories.

Austin's attitude to the construction of philosophical theories was a complex one and there was another side to it. For it is also worth asking whether there was any general theory underlying his investigation of ordinary language. We have seen that Wittgenstein offered an alternative to realism and conventionalism which may or may not count as a theory, depending on the strictness with which we use that word. Was there a general theory behind Austin's method too? I do not think so. At least, I was never aware of any such theory in discussion with him. It is true that he believed that ordinary language marks important distinctions. But who would deny that? It is also true that he thought that the first and most urgent task of philosophy was to investigate these distinctions. That, of course, is a matter of opinion and it would be denied by many philosophers of science. But these are mainly presuppositions of his method and they do not imply that there is nothing else that philosophers can do. What was conspicuously absent from his philosophy was any dominating theme, like ilttgenstein's powerful development of his alternative to realism and conventionalism.

If we had to choose between deep analysis and surface analysis or between theoretical and anti-theoretical philosophy, we would find it very difficult to make these choices. A philosopher who commits himself exclusively to one side or the other will neglect important facts or fail to notice important connections between them, and so he will impoverish his own work. But fortunately we do not have to make these extreme choices. We can adopt the style of our analysis to 
the nature of the subject matter. For example, in the philosophy of mind we can investigate the complex conceptual scheme that we use when talk about ourselves without attempting to construct a single theory that would unify all the highly differentiated material. Alternatively, we may seek a single theory even in this area, but if we do, we must accept the need to 'regiment' some of the facts in the way Quine recommends ${ }^{I}$. There is no need to asume that this 'regimentaion' will lead to what Wittgenstein calls 'contempt for the particular case ${ }^{2}$. "The fox knows many tricks, but the hedgehog knows one big trick" 3 . A philosopher is not forced to choose between these two strategies: he can use the one that suits his present inquiry best without comititing himself to never using the other.

(Christ Church, Oxford)

I. Quine: From a Logical Point of View.

2. Wittgenstein: Blue Book, near the beginning.

3. Archilochus: used by Isaiah Berlin as the motto of his hook on Tolstoy. 